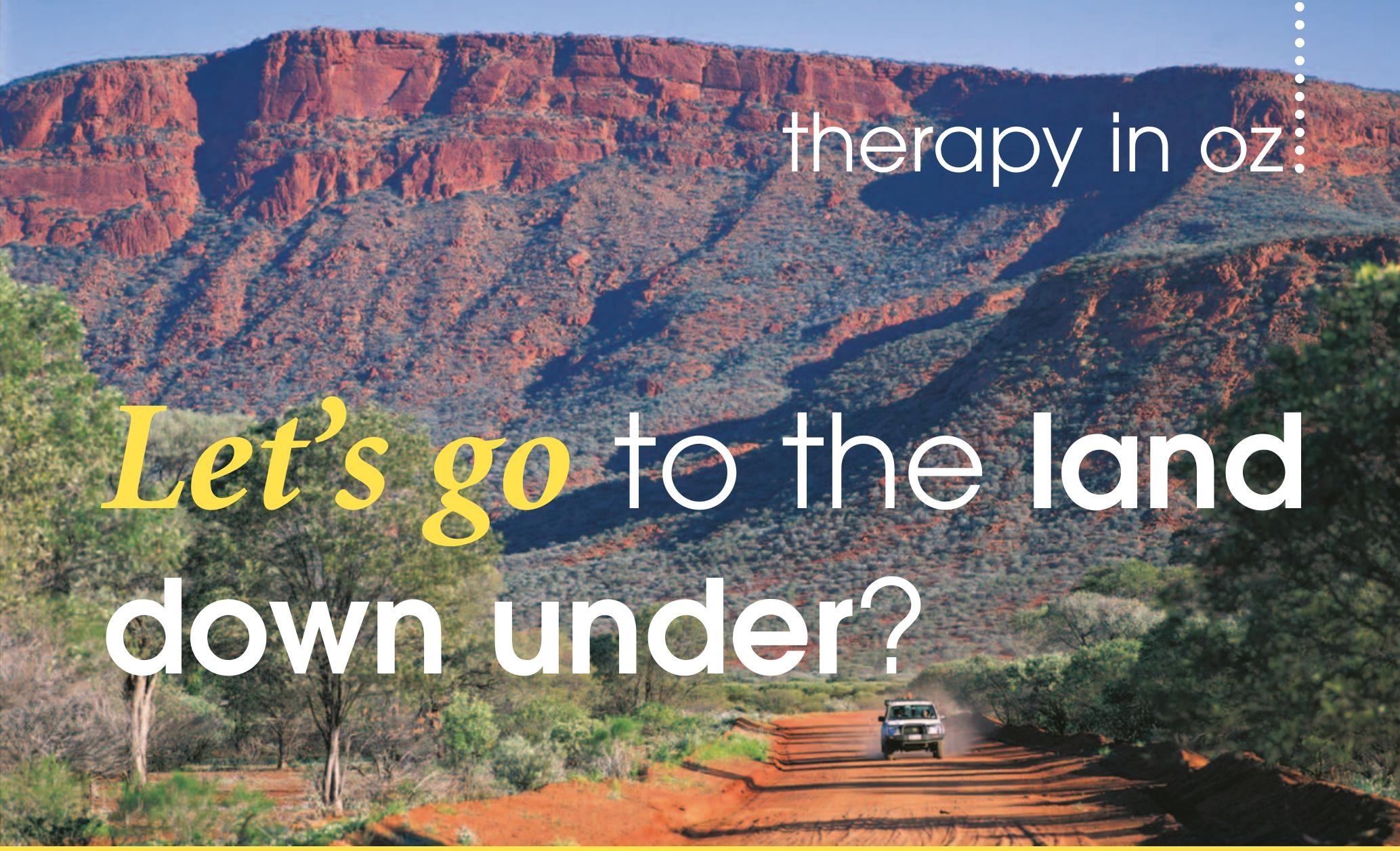

Endless golden beaches, dramatic deserts and sensational cities:

it's no wonder Australia holds an endless appeal for UK travellers.

Taking time out to travel down under is an attractive prospect for

all Brits - and well worth considering for British therapists, as Australia faces a dental therapist shortage. Kate Craig investigates.

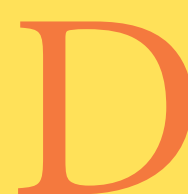

ental therapists have a higher profile in Australia than here in Britain. Unlike the UK, where registered therapists number $706^{1}$ in a population of 60 million (that's a ratio of around 1 therapist to every 85,000 people), there are thought to be over 1,500 therapists in Australia, ${ }^{2}$ although its population numbers only around 20 million (a ratio of 1 therapist to around 13,300 people).

This higher proportion of dental therapists can largely be attributed to therapists working in school dental programmes, providing dental care to children and adolescents. Until recently, therapists in all states other than Western Australia were restricted to working in the public sector, but recent reviews have opened the door for therapists in most states to move into private practice.

Dental therapists in Victoria, South Australia, Tasmania, the Northern Territory and Queensland are now able to work in private general dental practices, specialist paediatric and orthodontic practices, pre-school and community health programmes and hospital clinics, as well as the school service. This removal of restrictions on therapists makes working in Australia an even more attractive prospect for British therapists.

Australian therapist/hygienist Anthea Clarke, who has over 20 years' dental therapy experience and runs a recruitment company placing therapists and hygienists into private practices around Australia, says working as a therapist in Australia is very rewarding:

"There is an excellent standard of dentistry, high compliance from patients to regular dental treatment and everyone here is used to paying for treatment so acceptance of treatment is usually good," she explains.

Of course, outside the work arena, Australia has so much to offer. From stunning and mystical Uluru (Ayers Rock) to the iconic Sydney Opera House, the dramatic Blue Mountains and the mind-blowing Great Barrier Reef, Australia is a land of wonders. Working in Australia is a great way to take your time to see the country properly.

Unfortunately, however, despite the current shortage, British therapists wishing to work in
Australia must follow a rather convoluted registration process. There is no standard assessment process as yet for overseas qualified dental therapists. British therapists and hygienists must apply for registration from the dental board in the specific Australian state in which they wish to work and their competency is then assessed on a case-by-case basis by that state's dental board. If the therapist later wishes to work in another state, they must apply for registration in that state under a mutual recognition policy.

"Simplifying the process would be a great step forward," says Anthea.

With the natural tendency for the Australians and the British to spend time in each other's countries, Anthea feels the development of a reciprocal agreement between the UK and Australia would be beneficial to both countries.

"At the moment as dental therapists and hygienists we are unable to practise in our chosen professions without extra costs and often more study," says Anthea. "There is a shortage of therapists and hygienists in Australia and reciprocal rights would certainly 


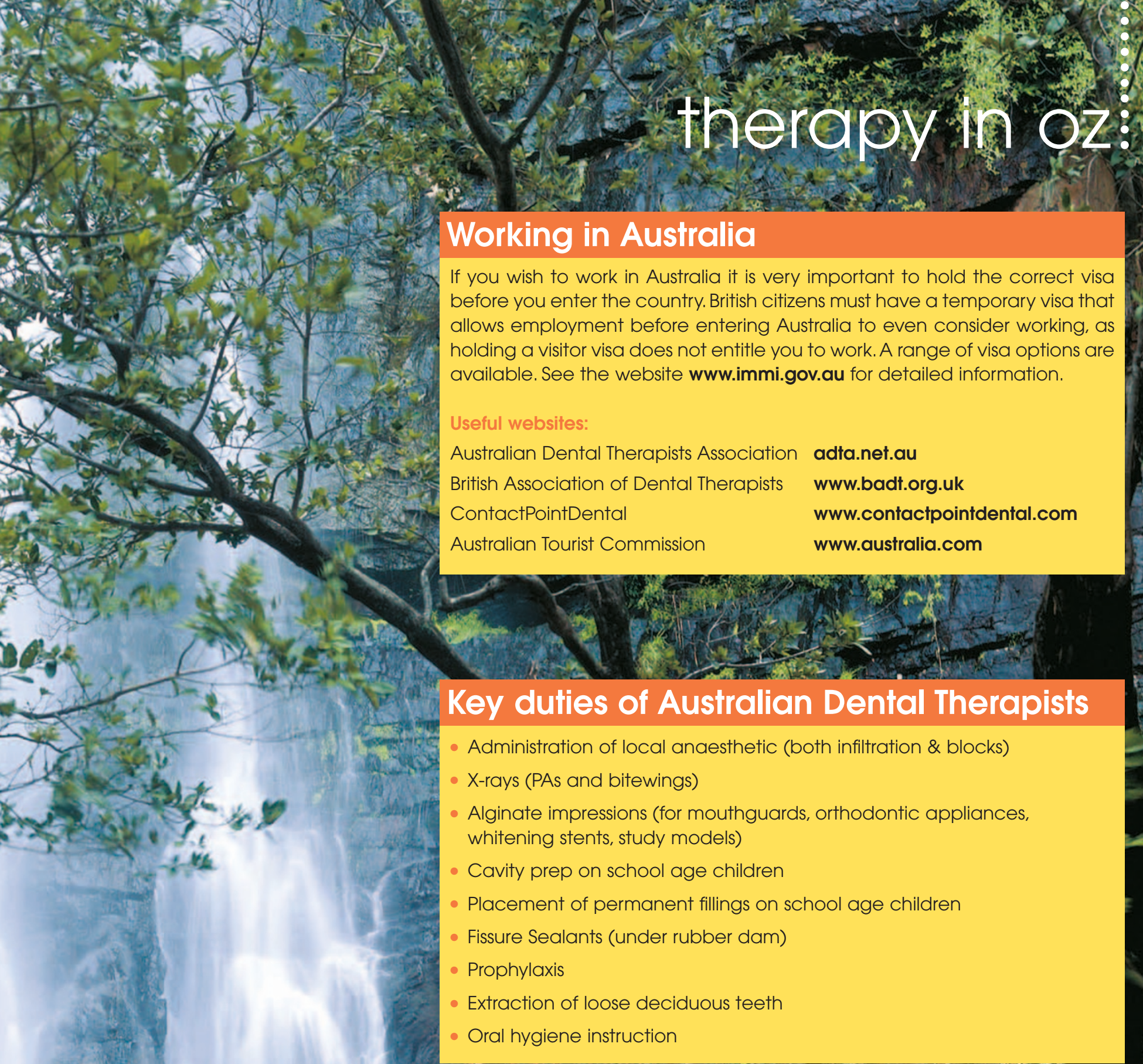

\section{Working in Australia}

If you wish to work in Australia it is very important to hold the correct visa before you enter the country. British citizens must have a temporary visa that Useful websites:

Australian Dental Therapists Association adta.net.au British Association of Dental Therapists

org.uk

ContactPointDenta

Australian Tourist Commission

www.contactpointdental.com www.qustralia.com

\section{It's a fact}

- Australia is approximately 17,000 kilometres from the UK by air.

- It takes approximately 20 hours to fly from London to Sydney and return flights start from around $£ 400$ one way or $£ 600$ return.

- Australia is the sixth largest country in the world and is 50 per cent larger than Europe, but has the lowest population density in the world - with just two people per square kilometre.

- Melbourne is gearing up to host the XVIII Commonwealth Games from 15-26 March 2006

- There are around 40 million kangaroos in Australia and 140 million sheep.

The magnificent Great Barrier Reef is as big as the total combined area of the United Kingdom and Ireland.

Uluru (Ayers Rock) is 3.6 kilometres long and 2 kilometres wide. It changes colour in different lights.

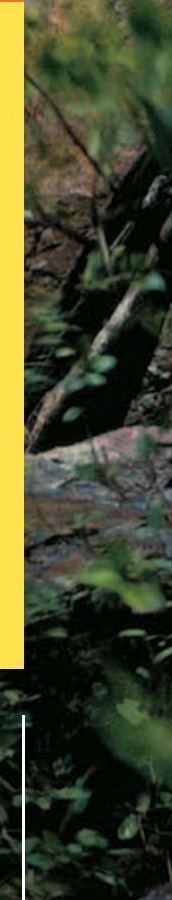

